OLIVEIRA, R.R. et al. Antioxidantes naturais em produtos cárneos. PUBVET, Londrina, V. 6, N. 10, Ed. 197, Art. 1324, 2012.

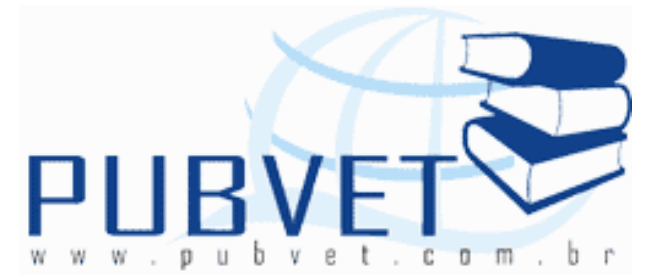

PUBVET, Publicações em Medicina Veterinária e Zootecnia.

\title{
Antioxidantes naturais em produtos cárneos
}

Raphael Rocha de Oliveira ${ }^{1}$, Moacir Evandro Lage ${ }^{2}$, Osvaldo José da Silveira Neto ${ }^{1}$, Michelle Costa de Sales ${ }^{3}$

${ }^{1}$ Alunos de Doutorado em Ciência Animal, Escola de Veterinária, Universidade Federal de Goiás

${ }^{2}$ Professor Adjunto, Escola de Veterinária, Universidade Federal de Goiás

${ }^{3}$ Graduada em Farmácia

\section{Resumo}

A oxidação lipídica resulta em mudanças nas características sensoriais desejáveis da carne in natura e derivados cárneos e é também relacionada a prováveis malefícios à saúde, como doenças cardíacas, derrames cerebrais e câncer. A adição de antioxidantes constitui prática mais comum para aumentar a estabilidade dos lipídios, sendo que, recentemente, as pesquisas têm se intensificado na busca de antioxidantes naturais. Objetiva-se com esta revisão de literatura mostrar os antioxidantes naturais mais freqüentemente utilizados na indústria de produtos cárneos, com foco na estrutura molecular, no mecanismo de ação e nas pesquisas que demonstraram a atividade e o potencial antioxidante de cada um deles. 
OLIVEIRA, R.R. et al. Antioxidantes naturais em produtos cárneos. PUBVET, Londrina, V. 6, N. 10, Ed. 197, Art. 1324, 2012.

\title{
Natural antioxidants in meat products
}

\begin{abstract}
The lipid oxidation results in changes in the desirable sensory characteristics of fresh beef and meat food and is also linked to potential health hazards, such as heart disease, strokes and cancer. The addition of antioxidants is more common practice to increase the stability of lipids, and, recently, research has intensified the search for natural antioxidants. The objective with this review of literature show the most frequently used natural antioxidants in the meat products industry, focusing on molecular structure, mechanism of action and research that demonstrated the activity and antioxidant potential of each.
\end{abstract}

\section{INTRODUÇÃO}

A carne é um dos alimentos mais importantes na dieta humana, não apenas como fonte de proteína de alta qualidade, mas também de minerais e todas as vitaminas do complexo B. Neste sentido, a carne tem merecido especial atenção pelo seu alto valor nutritivo, principalmente em relação à conservação de suas propriedades funcionais, a fim de garantir um produto final de boa qualidade para os consumidores e rentabilidade para a indústria cárnea.

Produtos ricos em lipídios têm chamado a atenção da comunidade científica por serem passíveis de sofrer reações autoxidativas. A carne in natura e derivados cárneos apresentam problemas quanto à oxidação lipídica no processamento e conservação, devido à sua concentração de ácidos graxos poliinsaturados.

A oxidação da carne resulta em mudança de sua coloração e alteração em outras características como maciez, sabor e perda de suco. É também relacionada a prováveis malefícios à saúde, já que o malonaldeído e os óxidos 
OLIVEIRA, R.R. et al. Antioxidantes naturais em produtos cárneos. PUBVET, Londrina, V. 6, N. 10, Ed. 197, Art. 1324, 2012.

de colesterol, produtos da oxidação lipídica, são responsáveis por doenças cardíacas, derrames cerebrais e câncer.

Para retardar ou minimizar a oxidação em carnes a indústria se utiliza de antioxidantes, principalmente os antioxidantes sintéticos. Pesquisas que se intensificaram a partir de 1980, demonstraram que estes compostos apresentaram toxicidade em ensaios in vivo, o que corroborou para a restrição da sua utilização em diversos países. Além disso, o aumento da consciência dos consumidores no que diz respeito à segurança dos aditivos alimentares, criou a necessidade para a identificação de alternativas naturais e, provavelmente, mais seguras, que apresentem atividade antioxidante em alimentos.

\section{REVISÃO DE LITERATURA}

A oxidação lipídica, também denominada de rancificação oxidativa ou autoxidação, é o principal processo pelo qual ocorre a perda da qualidade da carne e seus produtos, depois da deterioração microbiana. Contudo, enquanto as reações deteriorativas, microbiológicas e/ou enzimáticas, podem ser inibidas com o emprego de baixas temperaturas, a oxidação lipídica ocorre normalmente à temperatura de congelamento, embora numa velocidade reduzida. Além disso, este processo destrói as membranas intracelulares, diminuindo a suculência e o valor nutricional do alimento (PIEDADE, 2007).

A estabilidade oxidativa dos alimentos é dependente do equilíbrio entre a composição e concentração do substrato e a presença de pró-oxidantes. A remoção do oxigênio, inativação de enzimas, proteção contra luz e íons metálicos são importantes para evitar ou minimizar a oxidação lipídica. No entanto, estas medidas nem sempre são aplicáveis. A adição de antioxidantes constitui prática mais comum para aumentar a estabilidade dos lipídios (DECKER \& XU, 1999). 
OLIVEIRA, R.R. et al. Antioxidantes naturais em produtos cárneos. PUBVET, Londrina, V. 6, N. 10, Ed. 197, Art. 1324, 2012.

É necessária uma abordagem sobre a oxidação lipídica e seu mecanismo de ação para melhor compreensão da atuação dos antioxidantes naturais no combate a esse processo degradativo.

\subsection{Oxidação Lipídica}

O termo lipídios é usado normalmente para indicar, de forma pouco exata, uma ampla variedade de produtos orgânicos que possuem a característica comum de não serem solúveis em água e sim em solventes apolares (hexano, éter, clorofórmio). Os lipídios são formados por diversos compostos químicos bastante diferentes entre si, sendo os ácidos graxos a substância presente em maior quantidade. Os ácidos graxos são formados de uma cadeia hidrocarbonada, variando no comprimento, de 2 a 20 ou mais átomos de carbono, com um grupo carboxílico $(\mathrm{HO}-\mathrm{C}=0)$ a um extremo da cadeia e um grupo metílico ( $\mathrm{CH} 3$ ) no outro (SOUZA, 2006).

Os ácidos graxos são classificados como saturados (AGSs), monoinsaturados (AGMs) e poliinsaturados (AGPs), dependendo do número de duplas ligações. Destes, estão em maior parte nos lipídios os ácidos graxos saturados, seguidos pelos monoinsaturados, e somente uma pequena parte é de ácidos graxos poliinsaturados (TRINDADE, 2007).

A oxidação lipídica ocorre pela degradação dos ácidos graxos poliinsaturados. A rancificação oxidativa não ocorre normalmente com ácidos graxos saturados porque neste caso a formação de um radical livre é energeticamente desfavorável. Somente sob condições drásticas de temperatura, a formação do radical livre por ruptura da ligação C-H de uma cadeia carbônica saturada poderia ocorrer, já que esta ruptura exigiria aproximadamente $100 \mathrm{kcal} / \mathrm{mol}$ de energia. Entretanto, a presença de duplas ligações na cadeia carbônica dos ácidos graxos insaturados baixa a energia necessária para a ruptura homolítica das ligações $\mathrm{C}-\mathrm{H}$ na posição alílica para aproximadamente $60 \mathrm{kcal} / \mathrm{mol}$ (TRINDADE, 2007). 
OLIVEIRA, R.R. et al. Antioxidantes naturais em produtos cárneos. PUBVET, Londrina, V. 6, N. 10, Ed. 197, Art. 1324, 2012.

A taxa de oxidação é diretamente dependente do grau de insaturação dos ácidos graxos, ou seja, a taxa relativa de autoxidação do ácido oléico (18:1), ácido linoléico (18:2), ácido a-linolênico (18:3) é na ordem de 1:12:25 com base na formação de peróxidos e na ordem de 1:45:100 com base no consumo de oxigênio (TOZER, 2001).

Devido ao seu conteúdo de ácidos graxos insaturados, a carne é particularmente suscetível à deterioração oxidativa, à qual pode ser acelerada por processamentos tecnológicos anteriores a estocagem como o corte e cozimento, os quais rompem as membranas celulares do músculo facilitando a interação dos ácidos graxos insaturados com substâncias pró-oxidantes (PADILHA, 2007).

Em alimentos cárneos, a oxidação lipídica e do pigmento inicia-se após abate, quando a ação antioxidante do tecido cárneo encontra-se limitada pela cessação do fluxo sanguíneo. Assim os lipídios e o pigmento tornam-se susceptíveis à ação de pró-oxidantes, que são os radicais livres e espécies reativas do oxigênio. As alterações bioquímicas que acompanham a conversão do músculo em carne oferecem condições favoráveis para que ocorra a oxidação na fração mais insaturada de fosfolipídios nas membranas subcelulares, onde o balanço entre os fatores pró-oxidativos e a capacidade antioxidativa não está controlado, favorecendo a oxidação lipídica (LAGE, 2004).

A falência de sistemas enzimáticos responsáveis pela redução de radicais livres na célula muscular viva, predispõe a matriz tecidual à oxidação, tanto de lipídios quanto de outras substâncias, como a mioglobina, com a tranformação do íon ferroso em férrico, resultando em alteração na cor da carne, de um vermelho brilhante (oximioglobina) para um marrom acinzentado (metamioglobina), ao qual o consumidor tem aversão (LAGE, 2004).

Muitos autores sustentam que existe uma interdependência entre a oxidação lipídica e a oxidação da cor em carnes. A oxidação do pigmento pode catalizar a oxidação lipídica, assim como, os radicais livres produzidos durante a oxidação lipídica podem oxidar o átomo de ferro ou desnaturar a molécula de 
OLIVEIRA, R.R. et al. Antioxidantes naturais em produtos cárneos. PUBVET, Londrina, V. 6, N. 10, Ed. 197, Art. 1324, 2012.

mioglobina, alterando negativamente a cor dos produtos cárneos (O'GRADY et al., 2000).

Os produtos da oxidação lipídica são indesejáveis não somente pela produção de odores e sabores desagradáveis, geralmente denominados de ranço, como resultado da decomposição de lipídios e produção de compostos voláteis, mas também, pela destruição de constituintes essenciais, ocasionando o decréscimo do valor nutricional dos alimentos e a formação de compostos tóxicos durante o processamento (SOUZA, 2006).

A oxidação lipídica em carnes pode ser acompanhada através do valor de TBARS, visto que produtos primários de oxidação lipídica constituem-se principalmente de hidroperóxidos, os quais são rapidamente decompostos em várias substâncias reativas ao ácido 2-tiobarbitúrico (TBARS), particularmente carbonilas, sendo o malonaldeído o elemento mais importante (PADILHA, 2007).

O malonaldeído é muito reativo, podendo interagir através de ligações cruzadas com o DNA e proteínas, promovendo aberrações cromossômicas e redução da capacidade de síntese protéica. O malonaldeído pode ser formado in vivo ou pré-formado em alimentos. Existem estudos sugerindo que o malonaldeído seja cancerígeno (SHAMBERRGER et al., 1974) e mutagênico (MUKAI \& GOLDSTEIN, 1976). Este, juntamente com os óxidos de colesterol, tem chamado a atenção da comunidade cientifica devido á sua provável relação com a formação de câncer (PIEDADE, 2007).

\subsubsection{Mecanismo de oxidação lipídica}

A oxidação dos lipídios inicia-se nas ligações insaturadas dos ácidos graxos. O processo é tradicionalmente descrito como uma reação em cadeia constituída por três fases distintas: início, propagação e término.

Nas fases de iniciação e propagação, a presença de radicais livres, que são moléculas extremamente reativas, é decisiva. Essas formas reativas são normalmente produzidas durante o metabolismo do oxigênio nos tecidos e são 
OLIVEIRA, R.R. et al. Antioxidantes naturais em produtos cárneos. PUBVET, Londrina, V. 6, N. 10, Ed. 197, Art. 1324, 2012.

chamadas de espécies reativas de oxigênio. Estes compostos dividem-se em radicais ou não radicais, conforme o Quadro 1 . Alguns deles são produzidos durante o metabolismo aeróbio das células vivas, como o radical superóxido $\left(\mathrm{O}_{2}{ }^{--}\right)$, que é formado pela adição de um elétron extra ao oxigênio molecular $\left(\mathrm{O}_{2}\right)$, durante o processo de redução do oxigênio na cadeia respiratória mitocôndrial. Da mesma forma, os macrófagos, quando estimulados, produzem $\mathrm{O}_{2}$ e $\mathrm{H}_{2} \mathrm{O}_{2}$ durante o processo normal de fagocitose (COMBS, 1998).

QUADRO 1. Espécies reativas de oxigênio

\begin{tabular}{|l|l|}
\hline \multicolumn{1}{|c|}{ Radicais livres } & \multicolumn{1}{c|}{ Não radicais } \\
\hline Radical hidroxila $\left(\mathrm{OH}^{\bullet}\right)$ & Peróxido de hidrogênio $\left(\mathrm{H}_{2} \mathrm{O}_{2}\right)$ \\
Radical nítrico $\left(\mathrm{N}^{\bullet} \mathrm{O}\right)$ & Ácido hipocloroso $(\mathrm{HOCl})$ \\
Radical superóxido $\left(\mathrm{O}_{2}{ }^{-}\right)$ & Oxigênio singlete $\left({ }^{1} \mathrm{O}_{2}\right)$ \\
Radical peroxila $\left(\mathrm{ROO}^{\bullet}\right)$ & Ozônio $\left(\mathrm{O}_{3}\right)$ \\
Radical alcoxila $\left(\mathrm{RO}^{\bullet}\right)$ & \\
\hline
\end{tabular}

Mesmo apresentando pouca reatividade química, os compostos $\mathrm{O}_{2}$ e $\mathrm{H}_{2} \mathrm{O}_{2}$, quando expostos a determinados íons metálicos, como $\circ \mathrm{Fe}^{2+}$ e $\circ \mathrm{Cu}^{2+}$, geram um radical livre altamente reativo, o radical hidroxila $\left(\mathrm{HO}^{\circ}\right)$.

O radical hidroxila $\left(\mathrm{HO}^{\circ}\right)$ é provavelmente o radical livre mais importante para a iniciação do processo de oxidação nos tecidos animais, uma vez que ele pode rapidamente remover um átomo de hidrogênio do ácido graxo insaturado. Os principais alvos do radical hidroxila ( $\left.\mathrm{HO}^{\circ}\right)$ são os lipídios, especialmente os ácidos graxos insaturados da membrana celular, as proteínas e o DNA (COMBS, 1998).

MELO \& GUERRA (2002) descrevem o processo de oxidação conforme a FIGURA 1.

- Etapa de iniciação: ocorre formação de radicais livres, os quais atacam e abstraem um átomo de hidrogênio de um grupamento metila $\left(R_{1} H\right)$, 
OLIVEIRA, R.R. et al. Antioxidantes naturais em produtos cárneos. PUBVET, Londrina, V. 6, N. 10, Ed. 197, Art. 1324, 2012.

adjacente à dupla ligação do ácido graxo insaturado, deixando um elétron desemparelhado no carbono, gerando um radical alila $\left(\mathrm{R}_{1}{ }^{\circ}\right)$.

- Etapa de propagação: o radical alila $\left(R_{1}{ }^{\circ}\right)$ após rearranjo molecular seguido pela adição do oxigênio triplete $\left(\mathrm{O}_{2}\right)$, origina o radical peroxila $\left(\mathrm{R}_{1} \mathrm{OO} \mathrm{O}^{*}\right)$ Este, então, abstrai um átomo de hidrogênio do carbono a-metileno de outro ácido graxo insaturado adjacente, produzindo hidroperóxidos $\left(\mathrm{R}_{1} \mathrm{OOH}\right)$ e outro radical alila $\left(R_{2}{ }^{\circ}\right)$, que retroalimenta a reação. Desta forma, a degradação oxidativa lipídica é frequentemente descrita como um processo autocatalítico ou autooxidativo.

\begin{tabular}{|c|c|}
\hline Iniciação: & $\mathrm{R}_{1} \mathrm{H} \rightarrow \mathrm{R}_{1}^{\bullet}+\mathrm{H}^{\bullet}$ \\
\hline \multirow[t]{2}{*}{ Propagação: } & $\mathrm{R}_{1}^{\bullet}+\mathrm{O}_{2} \rightarrow \mathrm{R}_{1} \mathrm{OO}^{\bullet}$ \\
\hline & $\mathrm{R}_{1} \mathrm{OO}^{\circ}+\mathrm{R}_{2} \mathrm{H} \rightarrow \mathrm{R}_{2}{ }^{*}+\mathrm{R}_{1} \mathrm{OOH}$ \\
\hline \multirow[t]{2}{*}{ Terminação: } & $\mathrm{R}_{1}^{\bullet}+\mathrm{R}_{2}^{\bullet} \rightarrow \mathrm{R} 1-\mathrm{R} 2$ \\
\hline & $\mathrm{R}_{2}^{\bullet}+\mathrm{R}_{1} \mathrm{OO}^{\bullet} \rightarrow \mathrm{R}_{1} \mathrm{OOR}_{2}$ \\
\hline
\end{tabular}

FIGURA 1 - Esquema geral da autoxidação de ácidos graxos polinsaturados

- Etapa de terminação: é marcada pela interrupção das reações em cadeia, posto que, quando ocorre uma redução da quantidade de ácido graxo insaturado presente no sistema, os radicais livres ligam-se uns aos outros formando compostos estáveis. Os produtos finais são derivados da decomposição dos hidroperóxidos, como álcoois, aldeído, cetonas, ésteres e outros hidrocarbonetos. Aldeídos e outros compostos voláteis formados conferem sabor e odor desagradáveis ao alimento, afetando a qualidade do produto. 
OLIVEIRA, R.R. et al. Antioxidantes naturais em produtos cárneos. PUBVET, Londrina, V. 6, N. 10, Ed. 197, Art. 1324, 2012.

\subsection{Antioxidantes}

Antioxidantes são substâncias utilizadas para combater e retardar as alterações oxidativas nos produtos cárneos, que, embora manipulados e mantidos em condições adequadas de embalagem e temperatura, ficam expostos à deterioração de ordem intrínseca, promovida por ações de enzimas, oxigênio existente no meio, temperatura e luminosidade (SHIMOKOMAKI et al., 2006).

O FDA (Food and Drug Administration) define antioxidantes como substâncias utilizadas para preservar e estender o shelf-life, ou vida-deprateleira de alimentos que contêm lipídios oxidáveis, através do retardo da descoloração, rancidez e deterioração decorrentes da oxidação. Estas substâncias podem provir desde fontes comerciais até os mais exóticos compostos isolados naturalmente dos alimentos (ADEGOKE, 1998).

Por definição, atividade antioxidante é a capacidade de um composto ou composição inibir a oxidação lipídica (SHIMOKOMAKI et al., 2006).

\subsubsection{Histórico sobre o uso de antioxidantes}

O retardamento das reações oxidativas por certos compostos foi registrado em 1797 e esclarecido em 1817. O curso da rancificação de gorduras permaneceu desconhecido até a demonstração que o oxigênio atmosférico era o maior agente causador de oxidação do ácido graxo livre. No início do século $\mathrm{XX}$, estudos mostraram que a oxidação de triglicerídios altamente insaturados poderia provocar odor de ranço em óleo de peixe (BAILEY, 1996).

O conhecimento atual das propriedades de vários produtos químicos para prevenir a oxidação de gorduras e alimentos gordurosos começou com estudos durante a I Guerra Mundial e, pouco depois, por pesquisadores que testaram a atividade antioxidante de mais de 500 compostos. Esta pesquisa básica, combinada com a vasta importância da oxidação em praticamente 
OLIVEIRA, R.R. et al. Antioxidantes naturais em produtos cárneos. PUBVET, Londrina, V. 6, N. 10, Ed. 197, Art. 1324, 2012.

todas as operações de manufatura, desencadeou uma busca por aditivos químicos para controlar a oxidação, que ainda hoje está em curso (RAMALHO \& JORGE, 2006).

\subsubsection{Características desejáveis dos antioxidantes}

Centenas de compostos têm sido propostos para inibir a deterioração oxidativa das substâncias oxidáveis, mas estão sob a dependência de alguns requisitos para poderem incorporar produtos alimentícios, como: ter compatibilidade com os alimentos; solubilidade em meios apolares; ser de fácil incorporação; eficientes em baixas concentrações $(0,001$ a 0,01\%); manter as características sensoriais do alimento intactas; estáveis a processamentos térmicos e armazenamento; eficazes ao menos um ano à temperatura de 25 a $30{ }^{\circ} \mathrm{C}$; sua LD50 deve ser menor do que $1000 \mathrm{mg} / \mathrm{Kg}$ do peso corporal humano; não devem exercer nenhum efeito significativo no crescimento de animais experimentais, submetidos a um longo tempo de experimentação. Além disso, não podem ser tóxicos mesmo em doses muitos maiores das que normalmente seriam ingeridas no alimento; devem ser ativos em baixas temperaturas; econômicos e não podem causar efeitos fisiológicos negativos. $\mathrm{Na}$ escolha de um antioxidante deve-se considerar também outros fatores, incluindo legislação, custo e preferência do consumidor por antioxidantes naturais (ORDÓÑEZ et al., 2005).

Atualmente, a utilização de antioxidantes em produtos alimentícios é controlada pela legislação dos países ou padrões internacionais. Deste modo, apenas alguns compostos reconhecidos como seguros pelas organizações internacionais como a Food and Agriculture Organization (FAO), Joint Expert Committee (JECFA) e a Wordl Health Organization (WHO) são permitidos para o uso em alimentos.

A aprovação dos antioxidantes para a utilização em alimentos, requer estudos toxicológicos sobre a possibilidade de efeitos mutagênicos, teratogênicos e carcinogênicos (SOARES, 2002). 
OLIVEIRA, R.R. et al. Antioxidantes naturais em produtos cárneos. PUBVET, Londrina, V. 6, N. 10, Ed. 197, Art. 1324, 2012.

\subsubsection{Antioxidantes sintéticos}

Devido ao menor custo e sua eficiente ação, os compostos antioxidantes mais utilizados na indústria são polifenóis de origem sintética, com destaque para: butil-hidroxi-anisol (BHA), butil-hidroxi-tolueno (BHT), terc-butil-hidroxiquinona (TBHQ) e propil galato (PG), representados pela Figura 2.

O emprego de antioxidantes sintéticos em alimentos tem sido relacionado a efeitos deletérios ao organismo humano. Por isso, desde a década de 1980, tem aumentado a preocupação no sentido de obter substâncias naturais que tenham função antioxidante com a mesma eficiência dos sintéticos (SOUZA, 2006).

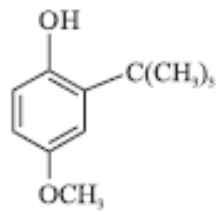

BHA

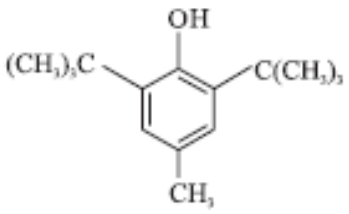

BHT

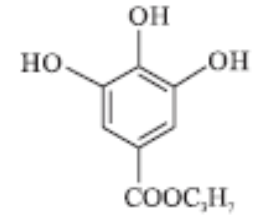

$\underline{\mathrm{PG}}$

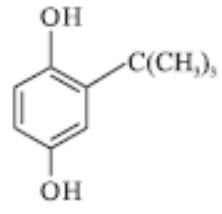

TBHQ

FIGURA 2 - Principais antioxidantes sintéticos utilizados (RAMALHO \& JORGE, 2006)

Em relação à toxicidade destes compostos, estudos realizados com o BHA, utilizando-se a via oral de administração, forneceram resultados negativos até 1982. Entretanto, nenhum destes estudos seria aceitável, por apresentarem duração insuficiente ou deficiências na seleção de tecidos para análises histopatológicas, em relação aos padrões atuais. A partir de 1983, a principal preocupação quanto à toxicidade deste composto, foi o desenvolvimento de tumores no estômago de roedores (WURTZEN, 1993).

A relevância para o homem dos efeitos do BHA no estômago de roedores foi discutida por vários autores, segundo os quais é pouco provável a ocorrência de efeitos semelhantes no homem, já que o nível de BHA necessário 
OLIVEIRA, R.R. et al. Antioxidantes naturais em produtos cárneos. PUBVET, Londrina, V. 6, N. 10, Ed. 197, Art. 1324, 2012.

para produzir efeitos carcinogênicos em roedores é muito superior aos níveis a que o homem está normalmente exposto através dos alimentos (WURTZEN, 1993). Segundo CRUCES-BLANCO et al. (1999), o BHA induziu hiperplasia gastrointestinal em roedores por um mecanismo desconhecido, mas em humanos, a relevância dessa observação não está clara.

O BHT é comercialmente utilizado na forma sólida, como cristal branco ou pó, constituindo-se no principal antioxidante encontrado em gorduras animais, cereais matinais, vitaminas, salames entre outros. O fígado, os pulmões e o sangue são os principais alvos de sua toxicidade. Em ratos, os efeitos do BHT sobre o fígado foram mais severos que os observados com o uso do BHA (WITSCHI, 1986).

O TBHQ foi testado em experimentos a longo prazo com ratos. O mesmo não causou alterações hemorrágicas semelhantes àquelas observadas em ratos expostos ao BHT. Quanto a efeitos adversos nos pulmões, enquanto o BHT produziu hiperplasia dos pneumócitos, o TBHQ não ocasionou nenhuma lesão neste órgão (SHERWIN, 1995). MADHAVI \& SALUNKHE (1995) atribuíram ao uso de TBHQ, a redução do nível de hemoglobina e a hiperplasia de células basais em ratos.

Por estes motivos, o uso de antioxidantes sintéticos em alimentos é limitado; TBHQ não é permitido no Canadá e na Comunidade Européia. No Brasil, o uso de antioxidantes sintéticos é controlado pelo Ministério da Saúde que limita $100 \mathrm{mg} / \mathrm{kg}$ para BHA, BHT e PG e $200 \mathrm{mg} / \mathrm{kg}$ para TBHQ como concentrações máximas permitidas (BRASIL, 1998).

O JECFA, a FAO e a WHO têm alterado nos últimos anos a ingestão diária aceitável (IDA) destas substâncias, com base nos resultados de pesquisas científicas demonstrando algum efeito tóxico associados a esses compostos. Entretanto, mediante a avaliação dos diversos estudos toxicológicos disponíveis, e que tais aditivos são utilizados normalmente em quantidades pequenas (100-200 mg/kg), e em alimentos cujo consumo em uma dieta normal é relativamente baixo, acredita-se que os mesmos, não ofereçam riscos à saúde humana (PADILHA, 2007). 
OLIVEIRA, R.R. et al. Antioxidantes naturais em produtos cárneos. PUBVET, Londrina, V. 6, N. 10, Ed. 197, Art. 1324, 2012.

Porém, é importante salientar que a IDA de um composto, assim como os níveis de uso permitido em diferentes alimentos, podem ser alterados a qualquer momento, desde que novos estudos sugiram tal necessidade. Deste modo, é extremamente relevante a continuidade dos estudos toxicológicos, e a realização periódica de estudos de ingestão de antioxidantes, assim como de outras classes de aditivos, a fim de se verificar se a IDA destes compostos não está sendo ultrapassada, garantindo assim a segurança de seu uso (SOUZA, 2006).

Tendo em vista os problemas que podem ser provocados pelo consumo de antioxidantes sintéticos, pesquisas têm sido dirigidas no sentido de encontrar produtos naturais com atividade antioxidante, os quais permitirão substituir os sintéticos ou fazer associações entre eles, com intuito de diminuir sua quantidade nos alimentos (SOARES, 2002).

\subsubsection{Antioxidantes naturais}

A análise da atividade antioxidante de compostos naturais teve início em 1952 em especiarias, ingredientes utilizados nos alimentos desde os primórdios da história, não somente para melhorar ou ressaltar suas características sensoriais, mas também para preservá-los (EXARCHOU et al., 2002).

Atualmente, os antioxidantes naturais mais importantes pertencem ao grupo dos compostos fenólicos, que são definidos como substâncias que apresentam em sua estrutura um anel aromático com uma ou mais hidroxila. Dentre eles, destacam-se os ácidos fenólicos, o tocoferol e os flavonóides como os antioxidantes mais comuns de fonte natural (MELO \& GUERRA, 2002).

Os antioxidantes naturais podem ser extraídos de vegetais e plantas. Muitas ervas e especiarias, utilizadas como condimentos em alguns produtos, são excelentes fontes de compostos fenólicos. Tais substâncias têm demonstrado alto potencial antioxidante, podendo ser usadas como conservantes naturais para alimentos (ANDREO \& JORGE, 2006) 
OLIVEIRA, R.R. et al. Antioxidantes naturais em produtos cárneos. PUBVET, Londrina, V. 6, N. 10, Ed. 197, Art. 1324, 2012.

Os compostos fenólicos exibem grande quantidade de propriedades fisiológicas, como antialergênica, antiaterogênica, antiinflamatória, antimicrobiana, antitrombótica, cardioprotetiva e vasodilatadora, mas o principal efeito dos compostos fenólicos tem sido atribuído à sua ação antioxidante em alimentos (BALASUNDRAM et al., 2006).

\subsubsection{Técnicas de extração de antioxidantes naturais}

Existem diversos métodos para a extração dos compostos antioxidantes em vegetais. Dentre estes, podem ser citados os tradicionais métodos de extração utilizando solventes orgânicos (como água, etanol, éter e metanol) e a extração supercrítica que mediante mudanças na pressão e na temperatura transforma o dióxido de carbono $\left(\mathrm{CO}_{2}\right)$ em fluido supercrítico para a extração (LEAL et al., 2003).

Sob o ponto de vista químico não há como selecionar a metodologia mais eficiente para a extração desses compostos, que podem sofrer a influência de diversos fatores. Dentre estes, podem ser citados a natureza do vegetal, o solvente empregado na extração, o tamanho das partículas, o tempo e a temperatura de extração (ANDREO \& JORGE, 2006).

Para a identificação e isolamento de compostos antioxidantes em fontes naturais (frutas, sementes e especiarias) é necessária a realização da extração com solventes de polaridades diferentes. As pesquisas enfocam essas extrações com o objetivo de comparar seus resultados e encontrar a melhor alternativa para sua aplicação em alimentos (ANDREO \& JORGE, 2006).

Algumas etapas preliminares devem ser realizadas para facilitar 0 processo de extração e conservar os compostos antioxidantes, que são sensíveis à ação da luz, oxigênio e calor. Os vegetais normalmente são desidratados, liofilizados ou congelados, e ainda peneirados ou moídos antes do processo de extração. Assim, os substratos atingem maior superfície de contato com o solvente de extração (MOURE et al., 2001). 
OLIVEIRA, R.R. et al. Antioxidantes naturais em produtos cárneos. PUBVET, Londrina, V. 6, N. 10, Ed. 197, Art. 1324, 2012.

A extração com solventes orgânicos é freqüentemente utilizada para o isolamento dos compostos antioxidantes em vegetais. Não existe sistema de extração com solventes que seja satisfatório para o isolamento de todos ou de classe específica de antioxidantes naturais, devido à variada natureza química destes compostos nos alimentos. A extração por solventes orgânicos torna-se agressiva ao ambiente devido aos resíduos gerados pelo seu uso. Também exige controle rigoroso de fatores como, a polaridade do solvente utilizado, o tempo e a temperatura de extração, pois podem ocorrer perda ou destruição dos compostos antioxidantes (ANDREO \& JORGE, 2006).

O fluido submetido à pressão e temperatura acima de seu ponto crítico torna-se supercrítico. Várias propriedades dos fluidos são alteradas sob estas condições, tornando-se parecidas com as de alguns gases e líquidos. A densidade do fluido supercrítico é similar a dos líquidos, sua viscosidade assemelha-se a dos gases e sua capacidade de difusão é intermediária entre os dois estados. Portanto, o estado supercrítico de fluidos pode ser definido como o estado no qual líquido e gás são indistinguíveis entre si (HERRERO et al., 2006).

Devido à sua baixa viscosidade e alta capacidade de difusão, os fluidos supercríticos apresentam propriedades de transporte melhores que os líquidos. Podem se difundir facilmente através de materiais sólidos, resultando em melhores rendimentos nas extrações. Outras vantagens, como a alta pureza dos extratos e a grande eficiência do processo, podem torná-los viáveis para aplicação em alimentos (LEAL et al., 2003).

O grande inconveniente da extração supercrítica reside na alta pressão necessária para a operação, que requer equipamentos excessivamente caros, elevando o custo do produto final (HERRERO et al., 2006). 
OLIVEIRA, R.R. et al. Antioxidantes naturais em produtos cárneos. PUBVET, Londrina, V. 6, N. 10, Ed. 197, Art. 1324, 2012.

\subsection{Antioxidantes naturais mais utilizados em alimentos}

\subsection{1 Ácidos Fenólicos}

Caracterizam-se por terem um anel benzênico, um grupamento carboxílico e um ou mais grupamentos de hidroxila e/ou metoxila na molécula, conferindo propriedades antioxidantes tanto para os alimentos como para o organismo, sendo indicados para o tratamento e prevenção do câncer, doenças cardiovasculares e outras enfermidades (VON GADOW et al., 1997).

Os ácidos fenólicos são divididos em três grupos. O primeiro é composto pelos ácidos benzóicos, que possuem sete átomos de carbono (C6-C1) e são os ácidos fenólicos mais simples encontrados na natureza; suas fórmulas gerais e denominações estão representadas na Figura 3. O segundo é formado pelos ácidos cinâmicos, que possuem nove átomos de carbono (C6-C3). São sete os mais encontrados no reino vegetal (Figura 4). O terceiro é composto pelas cumarinas, que são derivadas do ácido cinâmico por ciclização da cadeia lateral do ácido o-cumárico, conforme mostrado na Figura 5.

Os ácidos fenólicos, além de se apresentarem sob sua forma natural, podem também se ligar entre si ou com outros compostos, formando ácidos com boa atividade antioxidante (SOARES, 2002).

Antioxidantes fenólicos funcionam como seqüestradores de radicais e algumas vezes como quelantes de metais, agindo tanto na etapa de iniciação como na propagação do processo oxidativo. Os produtos intermediários, formados pela ação destes antioxidantes, são relativamente estáveis devido à ressonância do anel aromático apresentada por estas substâncias. Os compostos fenólicos e alguns de seus derivados são, portanto, eficazes para prevenir a oxidação (SOARES, 2002). 
OLIVEIRA, R.R. et al. Antioxidantes naturais em produtos cárneos. PUBVET, Londrina, V. 6, N. 10, Ed. 197, Art. 1324, 2012.

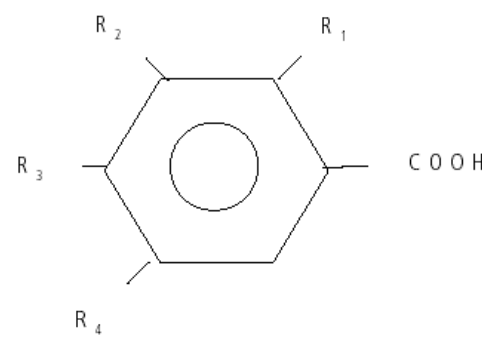

$\mathrm{R}_{1}=\mathrm{OH} \rightarrow$ Ácido Salicílico; $\mathrm{R}_{1}=\mathrm{R}_{4}=\mathrm{OH} \rightarrow$ Ácido Gentísico; $\mathrm{R}_{3}=\mathrm{OH} \rightarrow$ Ácido p-hidroxibenzóico; $\mathrm{R}_{2}=\mathrm{R}_{3}=\mathrm{OH} \rightarrow$ Ácido Protocatequínico; $\mathrm{R}_{2}=\mathrm{OCH}_{3}$; $\mathrm{R}_{3}=\mathrm{OH} \rightarrow$ Ácido Vanílico; $\mathrm{R}_{2}=\mathrm{R}_{3}=\mathrm{R}_{4}=\mathrm{OH} \rightarrow$ Ácido Gálico; $\mathrm{R}_{2}=\mathrm{R}_{4}=\mathrm{OCH}_{3}$; $\mathrm{R}_{3}=\mathrm{OH} \rightarrow$ Ácido Siríngico

FIGURA 3 - Estrutura molecular dos ácidos benzóicos

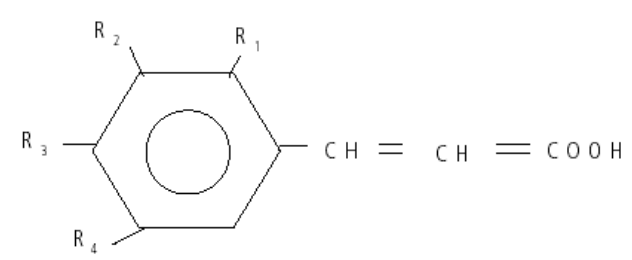

$\mathrm{R}_{1}=\mathrm{R}_{2}=\mathrm{R}_{3}=\mathrm{R}_{4}=\mathrm{H} \rightarrow$ Ácido cinâmico; $\mathrm{R}_{1}=\mathrm{OH} \rightarrow$ Ácido 0-cumárico; $\mathrm{R}_{2}=\mathrm{OH} \rightarrow$ Ácido m-cumárico; $\mathrm{R}_{3}=\mathrm{OH} \rightarrow$ Ácido p-cumárico; $\mathrm{R}_{2}=\mathrm{R}_{3}=$ $\mathrm{OH} \rightarrow$ Ácido Caféico; $\mathrm{R}_{2}=\mathrm{OCH}_{3} ; \mathrm{R}_{3}=\mathrm{OH} \rightarrow$ Ácido Ferúlico; $\mathrm{R}_{2}=\mathrm{R}_{4}=$ $\mathrm{OCH}_{3} ; \mathrm{R}_{3}=\mathrm{OH} \rightarrow$ Ácido Sinápico

FIGURA 4 - Estrutura molecular dos principais ácidos cinâmicos

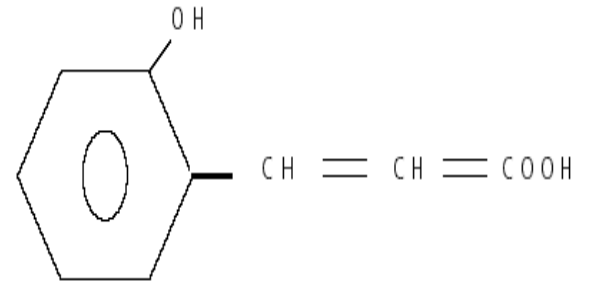

Ácido o-cumárico

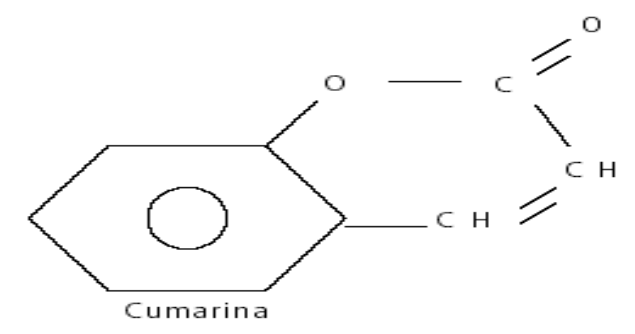

FIGURA 5 - Formação das cumarinas

Fonte: SOARES (2002)

$\mathrm{Na}$ tentativa de elucidar as diferenças de potencial existentes entre os ácidos fenólicos, foi realizada uma comparação quantitativa do comportamento cinético da inibição da oxidação de alguns ácidos benzóicos e cinâmicos quando aplicados em banha aquecida a $100^{\circ} \mathrm{C}$, com retirada de amostras em intervalos de tempo definidos para análise. Concluiu-se que, a atividade antioxidante dos compostos estudados apresentou a seguinte ordem: ácido caféico $>$ 3,4-diidroxibenzóico $>$ sinápico $>$ siríngico $>$ ferúlico $>p$-cumárico $>$ vanílico (MARINOVA \& YANISHLIEVA, 1992).

Em avaliação do potencial dos ácidos caféico, protocatequínico, $p$ hidroxibenzóico, ferúlico e $p$-cumárico em banha, na concentração de 200 
OLIVEIRA, R.R. et al. Antioxidantes naturais em produtos cárneos. PUBVET, Londrina, V. 6, N. 10, Ed. 197, Art. 1324, 2012.

$\mathrm{mg} / \mathrm{kg}$, os ácidos caféico e protocatequínico apresentaram atividade antioxidante maior que o a-tocoferol e o BHT na mesma concentração (VON GADOW et al., 1997).

\subsubsection{Vitamina E}

O termo vitamina E é usado como uma alusão genérica a todos os tocóis e tocotrienóis que exibem a atividade biológica do a-tocoferol. São ao todo oito compostos, todos lipossolúveis, conhecidos como $a, \beta, y$ e $\delta$ tocoferóis e $a, \beta, y$ e $\delta$ tocotrienóis (BATISTA et al., 2007). As moléculas de tocoferóis e tocotrinóis são mostradas nas Figuras 6 e 7. A presença do sinal " \{\} " na figura 7 foi usado pra mostrar a diferença na estrutura do tocoferol e tocotrienol.

Os tocoferois são antioxidantes pertencentes a um grupo composto por quatro distintos isômeros, que se diferenciam pelo número e posição do grupo metila ligado ao anel fenólico. No entanto, dentre todos os tocoferóis conhecidos, o a-tocoferol tem sido considerado como o mais ativo biologicamente, constituindo-se no principal antioxidante lipossolúvel naturalmente presente no músculo. Além de maior atividade biológica quando comparado aos demais, apresenta maior índice de absorção intestinal, maior deposição nos tecidos e menor excreção fecal, além de ser oxidado mais lentamente (DECKER \& XU, 1999).

A vitamina $E$ apresenta-se como componente estrutural da membrana e a maior parte dos demais agentes antioxidantes encontra-se no meio intracelular. A presença da vitamina E na membrana é de extrema importância, pois exerce um efeito protetor contra a degradação lipídica e, conseqüentemente, contra o extravasamento de material intracelular, que comprometeria o funcionamento do organismo (BATISTA et al., 2007). 
OLIVEIRA, R.R. et al. Antioxidantes naturais em produtos cárneos. PUBVET, Londrina, V. 6, N. 10, Ed. 197, Art. 1324, 2012.

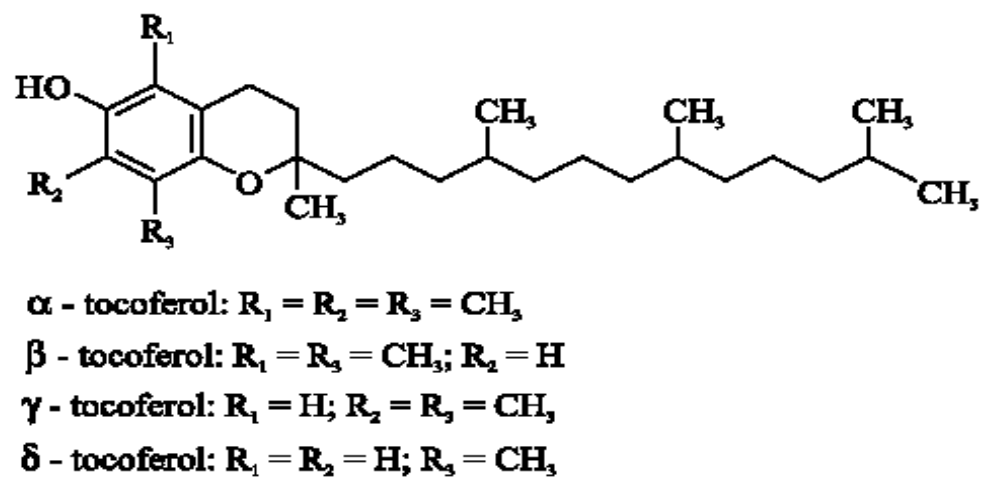

FIGURA 6 - Estrutura molecular dos tocoferóis (RAMALHO \& JORGE, 2006)

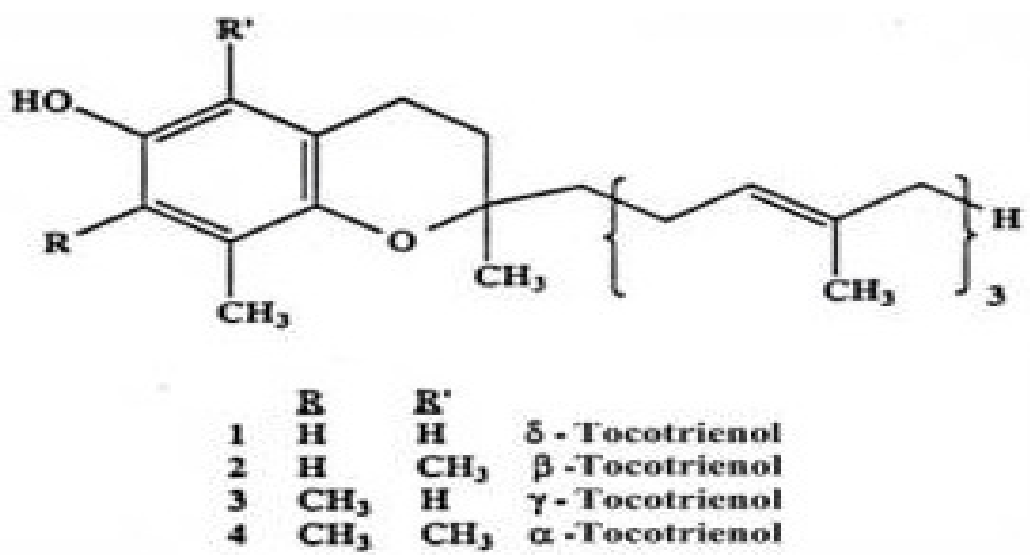

FIGURA 7 - Estrutura molecular dos tocotrienóis (BIANCHINI \& PENTEADO, 2003)

Devido a sua natureza lipofílica, o a-tocoferol possui a propriedade de acumular-se no interior das membranas, sendo transportado por lipoproteínas, essencialmente as de baixa densidade (LDL), armazenando-se em vários tecidos como no fígado, tecido adiposo e músculo (BIANCHINI \& PENTEADO, 2003).

A ação antioxidante da vitamina E no processo de peroxidação lipídica está essencialmente relacionada à captura de radicais peroxila e alcoxila. A atividade antioxidante dos tocoferóis é principalmente devida à capacidade de doar seus hidrogênios fenólicos aos radicais livres lipídicos, impedindo a formação de hidroperóxidos, interrompendo a propagação em cadeia. A 
OLIVEIRA, R.R. et al. Antioxidantes naturais em produtos cárneos. PUBVET, Londrina, V. 6, N. 10, Ed. 197, Art. 1324, 2012.

capacidade de essa vitamina impedir a oxidação depende de sua concentração no tecido (BATISTA et al., 2007).

A vitamina E é comumente usada na suplementação dietética de animais, comercialmente na forma sintética all-rac-a-tocoferol. Estes ésteres são resistentes à oxidação, mas não exibem atividade antioxidante. Porém, quando hidrolizados no intestino, liberam a forma nativa do a-tocoferol, recuperando, deste modo, a sua atividade (SOUZA \& SILVA, 2006).

BURTON et al. (1998), comparando a concentração de a-tocoferol plasmática e tecidual em humanos, mediante suplementação da vitamina natural e sintética, observaram que a forma natural apresentava disponibilidade, aproximadamente, duas vezes maior que a sintética. A vitamina E é considerada um potente antioxidante, reagindo 200 vezes mais rápido contra radicais peroxila (ROO) em relação a antioxidantes sintéticos (BIANCHINI \& PENTEADO, 2003).

O a-tocoferol foi utilizado em salsicha elaborada com carne de ave e suína, e proporcionou uma proteção antioxidante significativamente maior quando comparado às amostras controle (sem antioxidante), sendo tão eficiente quanto os antioxidantes sintéticos BHA e BHT em retardar a oxidação (RESSURRECCION \& REYNOLDS, 1990).

Houve redução de $50 \%$ no índice de TBARS em presuntos cozidos, obtidos de animais que receberam suplementação, os quais sofreram oxidação por método de indução com $37^{\circ} \mathrm{C}$ durante 200 minutos (DE WINNE \& DIRINCK, 1997). Em presuntos com cura a seco, de suínos que receberam dietas com 200 mg de vitamina E por kg de ração, fornecidas durante 42 dias antes do abate, depois de fatiados, embalados e armazenados a $4^{\circ} \mathrm{C}$ durante nove dias, as amostras suplementadas apresentaram redução de $55 \%$ no índice de TBARS, quando comparadas ao controle (ISABEL et al., 1999).

Em um estudo sobre o efeito da vitamina $E$ na sua forma de a-tocoferol sobre a oxidação lipídica de carne bovina, a porcentagem de oxigênio atmosférico foi alterada para níveis de $20 \%, 40 \%, 60 \%$ ou $80 \%$ de $\mathrm{O}_{2}$, adicionando ou não a-tocoferol. Sem a adição de a-tocoferol, a oxidação 
OLIVEIRA, R.R. et al. Antioxidantes naturais em produtos cárneos. PUBVET, Londrina, V. 6, N. 10, Ed. 197, Art. 1324, 2012.

lipídica das peças aumentou significativamente entre sete e 10 dias de estocagem, quando o conteúdo de oxigênio atmosférico foi modificado em $40 \%, 60 \%$ e $80 \%$. A adição de a-tocoferol foi de 300 e $3000 \mathrm{mg} / \mathrm{kg}$ de lipídio, tendo como veículo azeite de oliva. A adição de a-tocoferol exógeno conduziu a uma redução $(p<0,05)$ da oxidação lipídica em peças bovinas estocadas em altos níveis de oxigênio atmosférico, mas não foi observado efeito positivo com a adição de a-tocoferol quando as peças foram submetidas a baixas pressões (O'GRADY et al., 2000).

Foi observado, através da comparação de bovinos suplementados com a-tocoferol (1.000 mg/cabeça/dia, por 98 dias) e animais controles (sem suplementação), a diminuição do conteúdo de colesterol, indicando que o a tocoferol pode ter efeito no metabolismo do colesterol. Além disso, a suplementação com a-tocoferol retardou a oxidação da mioglobina, e resultou em menor perda de suco nos músculos analisados (LAGE, 2004).

Houve redução na produção de óxidos de colesterol, durante o armazenamento de presunto cozido, obtidos de suínos que receberam suplementação de 200 mg de vitamina E por kg de ração (SOUZA \& SILVA, 2006).

\subsubsection{Antioxidantes da Família Lamiaceae}

A família Lamiaceae consiste em aproximadamente 3500 espécies de plantas que são nativas principalmente na área do Mediterrâneo, embora algumas tenham origem na Austrália, no Sudoeste da Ásia e na América do Sul. Como exemplos, podem ser citadas espécies de alecrim, sálvia, orégano, tomilho, manjericão, manjerona, menta, dentre outras, as quais são estudadas devido às suas propriedades antioxidantes, antimicrobianas e medicinais (MARIUTTI \& BRAGAGNOLO, 2007).

De acordo com a legislação brasileira, não há limitação para o uso de condimentos utilizados na formulação de produtos cárneos com ação antioxidante (BRASIL, 1998). 
OLIVEIRA, R.R. et al. Antioxidantes naturais em produtos cárneos. PUBVET, Londrina, V. 6, N. 10, Ed. 197, Art. 1324, 2012.

Podem ser isolados dezenas de compostos com características antioxidantes, principalmente em alecrim, sálvia, orégano e tomilho. Dos principais compostos fenólicos presentes em extrato metanólico de orégano, os três mais importantes são o ácido caféico, ácido rosmarínico e carvacrol. Através da analise da composição do tomilho foram detectados mais de 40 compostos fenólicos, dentre os quais os principais componentes foram $\rho$ cimeno, $\gamma$-terpineno, timol, carvacrol e $\beta$-carofileno (SKERGET et al., 2005).

Os ácidos carnósico e rosmarínico foram indicados como sendo os constituintes do alecrim de maior atividade antioxidante. Os extratos de antioxidantes comerciais do alecrim estão disponíveis como um pó fino. Dependendo da quantidade de atividade dos antioxidantes, eles são recomendados para o uso nas concentrações entre 100 e 1000 ppm do produto processado (MARIUTTI \& BRAGAGNOLO, 2007).

As propriedades antioxidantes dos membros da família Lamiaceae são atribuídas principalmente aos compostos fenólicos. Desta forma, sua ação será semelhante ao que foi mostrado anteriormente, ou seja, interrompendo a cadeia de radicais livres na etapa de iniciação do processo oxidativo.

Os condimentos podem ser adicionados aos alimentos sob várias formas, como condimentos íntegros, condimentos moídos ou extratos isolados dos condimentos. Cada uma destas formas pode apresentar diferentes compostos, em quantidades variadas e com diferentes atividades antioxidantes. Quando usados na forma de extratos, os compostos presentes dependem, principalmente, do método de extração e do solvente utilizado. Além disso, a concentração e a composição dos compostos presentes nos condimentos sofrem a influência de alguns fatores como o cultivar, a origem geográfica, a estação climática, as práticas agrícolas e a parte da planta que foi utilizada. Finalmente, a ação antioxidante de cada condimento depende ainda da metodologia analítica utilizada para sua determinação (MADSEN \& BERTELSEN, 1995). 
OLIVEIRA, R.R. et al. Antioxidantes naturais em produtos cárneos. PUBVET, Londrina, V. 6, N. 10, Ed. 197, Art. 1324, 2012.

A oleoresina de alecrim, usada em salsichas de peru estocadas a $4^{\circ} \mathrm{C}$, mostrou como resultados valores de TBARS semelhantes aos obtidos com o uso de uma mistura comercial de BHA e BHT (BARBUT et al., 1985).

Em carne bovina, foram utilizados extratos lipossolúveis comerciais de sálvia e de alecrim e, tanto os extratos puros de cada condimento, como a mistura dos dois, mostraram-se efetivos na inibição da oxidação dos lipídios (WONG et al., 1995).

Em hambúrgueres de suíno cru e após cocção, pré-tratados com extrato etanólico de tomilho, de sálvia, de manjericão ou de gengibre, apresentaram teores significativamente menores de peróxidos e TBARS em relação a um controle sem adições, tanto durante a estocagem refrigerada, quanto durante a estocagem congelada (EL-ALIM et al., 1999).

Em hambúrgueres de carne bovina, tanto com adição de alecrim em pó, como com adição de extrato comercial de alecrim e de orégano, houve inibição de coloração anormal e da oxidação de lipídios, medida pela formação de TBARS (SÁNCHEZ-ESCALANTE et al., 2003).

Houve efeito antioxidante do extrato de alecrim em hambúrgueres suínos pré-cozidos sob condições de varejo (10 dias, $4^{\circ} \mathrm{C}$, exposto ao ar), em que os atributos de qualidade sensoriais foram aceitáveis até o final do período (NISSEN et al., 2004).

Extratos hidrossolúvel e lipossolúvel de alecrim eliminaram a rancidez, de acordo com os valores de TBARS, em almôndegas de carne bovina durante um período de 12 dias a $8^{\circ} \mathrm{C}$ (FERNÁNDEZ-LOPEZ et al., 2005).

A atividade antioxidante de um extrato comercial de alecrim foi avaliada em salsichas de porco cruas, armazenadas sob refrigeração ou sob congelamento, e em salsichas pré-cozidas, armazenadas sob congelamento, sendo que os resultados obtidos foram semelhantes ou melhores aos obtidos com uma mistura de BHA e BHT, quando analisados em relação ao valor de TBARS e à perda de coloração vermelha (SEBRANEK et al., 2005).

Os extratos de alecrim em solventes de diferentes polaridades apresentaram atividade antioxidante superior ou semelhante ao BHA, BHT, 
OLIVEIRA, R.R. et al. Antioxidantes naturais em produtos cárneos. PUBVET, Londrina, V. 6, N. 10, Ed. 197, Art. 1324, 2012.

TBHQ ou PG. Resultados semelhantes foram obtidos para a sálvia, para o orégano e para o tomilho (MARIUTTI \& BRAGAGNOLO, 2007).

Apesar da atividade antioxidante das plantas da família Lamiaceae, conforme mostrado nesta revisão, condimentos têm aplicações limitadas em alimentos, pois essas ervas imprimem um sabor característico, sendo necessárias medidas de desodorização (MOURE et al., 2001).

\subsubsection{Flavonóides}

Os flavonóides são os compostos mais diversificados do reino vegetal. Neste grupo encontram-se as antocianinas, flavonas, flavonóis e, com menor freqüência, as auronas, calconas e isoflavonas, dependendo do lugar, número e combinação dos grupamentos participantes da molécula (SOARES, 2002), conforme exemplificado na Figura 8.

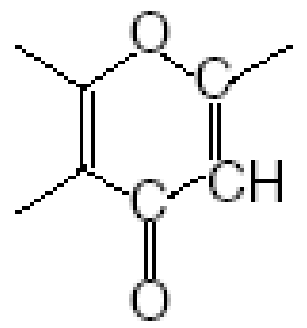

Flavona

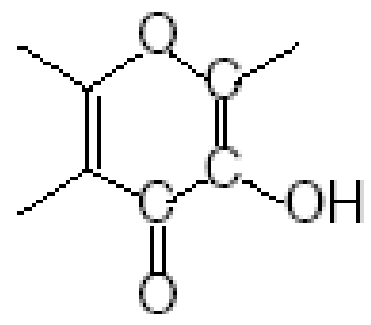

Flavonol

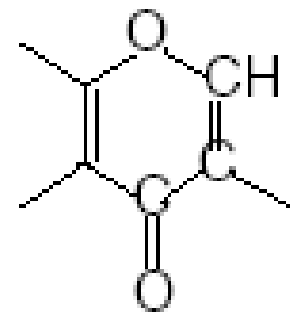

Isoflavona

FIGURA 8 - Estrutura molecular dos flavonóides: flavona, flavonol e isoflavona. Adaptado de SIVAM (2002)

Foram isolados flavonóides com características antioxidantes em acerola (VENDRAMINI \& TRUGO, 2004), maçã, tomate e cebola (AGOSTINI et al., 2004), romã (JARDINI, 2005), caju (BROINIZI et al., 2007), plantas do gênero acácia (ANDRADE et al., 2007) e uva (ABE et al., 2007), dentre outros.

As antocianinas são flavonóides amplamente distribuídos na natureza. Atualmente, conhecem-se 20 antocianinas, mas apenas seis delas são 
OLIVEIRA, R.R. et al. Antioxidantes naturais em produtos cárneos. PUBVET, Londrina, V. 6, N. 10, Ed. 197, Art. 1324, 2012.

importantes para a tecnologia dos alimentos: pelargonidina, cianidina, delfinidina, peonidina, etunidina e malvidina (SOUZA, 2006), conforme mostrado na Figura 9.

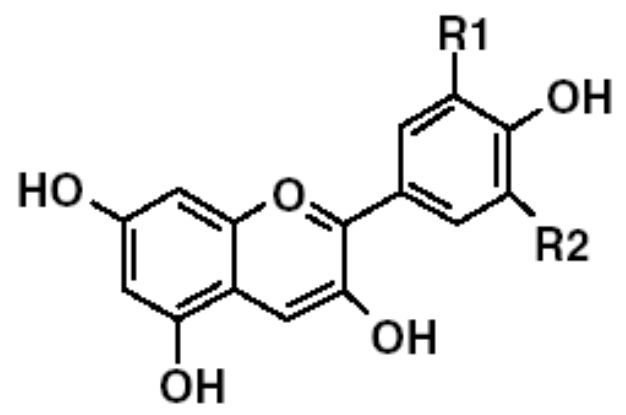

\begin{tabular}{lll}
\hline Antocianinas & $\mathrm{R} 1$ & $\mathrm{R} 2$ \\
\hline pelargonidina & $\mathrm{H}$ & $\mathrm{H}$ \\
cianidina & $\mathrm{H}$ & $\mathrm{OH}$ \\
delfinidina & $\mathrm{OH}$ & $\mathrm{OH}$ \\
peonidina & $\mathrm{OCH}_{3}$ & $\mathrm{H}$ \\
petunidina & $\mathrm{OCH}_{3}$ & $\mathrm{OH}$ \\
malvidina & $\mathrm{OCH}_{3}$ & $\mathrm{OCH}$ \\
\hline
\end{tabular}

FIGURA 9 - Estrutura molecular das principais antocianinas. Adaptado de SIVAM (2002)

Distribuídas em diversas famílias vegetais, as antocianinas são, em sua maioria, responsáveis pelas multicores das pétalas de flores e frutos de vegetais superiores. São consideradas como aditivos eficazes e seguros na indústria alimentícia, usados essencialmente para conferir coloração adequada e desejada a produtos alimentícios. Por esta razão, são poucos os trabalhos mostrando a ação antioxidante desses compostos em produtos cárneos (KAHKONEN, 2003).

As propriedades benéficas dos flavonóides podem ser atribuídas à sua capacidade de doar átomos de hidrogênio e, portanto, inibir as reações em cadeia provocadas pelos radicais livres, e também por ser quelantes de metais (MELO \& GUERRA, 2002).

A galangina e a quercetina, flavonóides presentes em orégano, foram identificados como agentes antimutagênicos contra o Trp-P-2, que é um composto carcinógeno comumente presente nas dietas humanas, sendo formado durante a cocção dos alimentos, principalmente carnes (SAMEJIMA et al., 1995). 
OLIVEIRA, R.R. et al. Antioxidantes naturais em produtos cárneos. PUBVET, Londrina, V. 6, N. 10, Ed. 197, Art. 1324, 2012.

\subsubsection{Fitatos}

Os fitatos representam uma classe complexa de compostos de ocorrência natural formados durante o processo de maturação de sementes e grãos de cereais. Nas sementes de leguminosas o ácido fítico contém aproximadamente $70 \%$ do conteúdo de fosfato, sendo estruturalmente integrado com proteínas e/ou minerais na forma de complexos (SILVA \& SILVA, 1999).

A habilidade do fitato em ligar-se a metais, particularmente ao ferro, pode explicar sua ação antioxidante e anticarcinogênica. O fitato é um poderoso inibidor da produção de radical hidroxila $(-\mathrm{OH})$ mediada pelo ferro, devido a sua capacidade de formar quelato com o ferro, tornando-o cataliticamente inativo. Além disso, o ácido fítico altera o potencial redox do ferro mantendo-o na forma férrica $\left(\mathrm{Fe}^{3+}\right)$. Este efeito oferece proteção contra danos oxidativos, visto que $0 \mathrm{Fe}^{2+}$ causa produção de radicais e oxidação de lipídios, enquanto o $\mathrm{Fe}^{3+}$ é relativamente inerte (EMPSON et al., 1991).

Foi feito por HARBACH et al. (2007), um estudo sobre os efeitos da dieta de germe de milho, que continha ácido fítico, sobre a estabilidade oxidativa do lipídio no corte longissimus dorsi de suínos. As rações de germe de milho foram preparadas no nível de uma substituição de $0 \%$, de $10 \%$, de $20 \%$ e de $40 \%$ e oferecidas a 24 animais por 25 dias antes do abate. A carne dos animais alimentados com germe de milho apresentou significativa inibição da oxidação. Os cortes, provenientes dos animais que tiveram $40 \%$ da dieta substituída por germe de milho, tiveram sua oxidação reduzida em $63 \%$ em relação aos controles.

\subsubsection{Carotenóides}

Os carotenóides (carotenos e xantofilas) são pigmentos multicoloridos encontrados em diversos vegetais (frutas, sementes, tubérculos). 0 principal mecanismo antioxidante destes compostos está relacionado à sua habilidade 
OLIVEIRA, R.R. et al. Antioxidantes naturais em produtos cárneos. PUBVET, Londrina, V. 6, N. 10, Ed. 197, Art. 1324, 2012.

de inativar $\mathrm{O}_{2}$ singlete. Mas, como o $\mathrm{O}_{2}$ singlete não é o mais importante agente pró-oxidante do músculo, os carotenóides possuem um potencial limitado para atuarem na estabilidade oxidativa de produtos cárneos (BEMAMOTZ \& FISHLER, 1998).

\subsubsection{Vitamina C}

A vitamina C ou ácido ascórbico é hidrossolúvel e termolábil. É encontrada na natureza sob duas formas: reduzida ou oxidada (ácido deidroascórbico); ambas são igualmente ativas, porém a forma oxidada está muito menos difundida nas substâncias naturais (CASTILHO, 2006).

Ácido ascórbico e seus sais funcionam como antioxidantes pela capacidade de reagirem com o oxigênio livre, removendo-o do sistema, resultando em diminuição das reações de auto-oxidação por eliminação do suprimento de oxigênio disponível. Seu efeito é claramente percebido em sistemas fechados ou com pouco oxigênio. Ao agir como removedor de oxigênio, o ácido ascórbico é oxidado e se transforma em ácido deidroascórbico. O ácido ascórbico também atua sinergisticamente com agentes complexantes, diminuindo o estado de oxidação de alguns metais, reduzindo a atividade catalítica deles. (BOBBIO \& BOBBIO, 2001).

Nos produtos cárneos curados com nitrito, o ácido ascórbico e seus sais ajudam na formação e estabilidade da cor característica, além de acelerarem o processo de cura. Não é recomendável, no entanto, o uso direto do ácido, mas sim o seu sal, o ascorbato (CASTILHO, 2006).

\section{CONSIDERAÇÕES FINAIS}

A oxidação lipídica e do pigmento inicia-se após abate, quando a ação antioxidante do tecido cárneo encontra-se limitada pela cessação do fluxo sanguíneo. Assim os lipídios e o pigmento tornam-se susceptíveis a ação de pró-oxidantes, que são os radicais livres e espécies reativas do oxigênio. 
OLIVEIRA, R.R. et al. Antioxidantes naturais em produtos cárneos. PUBVET, Londrina, V. 6, N. 10, Ed. 197, Art. 1324, 2012.

A oxidação da carne é importante não só para a mudança de coloração como para alteração em outras características como maciez, sabor e perda de suco. Além de prováveis malefícios à saúde, já que o malonaldeído e os óxidos de colesterol são produtos da oxidação lipídica e responsáveis por doenças cardíacas derrames cerebrais e câncer.

Para retardar ou minimizar a oxidação em carnes a indústria se utiliza de antioxidantes. Existem antioxidantes sintéticos e naturais, sendo os primeiros mais baratos e mais estáveis que os naturais, porém são considerados cancerígenos. Este fato estimulou a maior utilização de antioxidantes naturais como ácidos fenólicos, tocoferois, condimentos, flavonóides, taninos e outros.

Nas últimas décadas, como medida preventiva para o controle de reações oxidativas, têm merecido destaques em inúmeras pesquisas, o isolamento e a busca de novos antioxidantes oriundos de fontes vegetais, descobrindo-se que estes compostos possuem eficácia similar ou até maior que a de antioxidantes sintéticos, além de atuarem fisiologicamente como auxiliares na prevenção de doenças.

O desafio para futuras pesquisas é encontrar um antioxidante natural que seja estável, permitindo a estocagem de produtos cárneos por longo tempo. Devem também ser estudados e aperfeiçoados os processos de extração, visando reduzir custos, o que viabilizará o uso de antioxidantes naturais como alternativa eficiente e segura para o controle da oxidação lipídica.

\section{REFERÊNCIAS BIBLIOGRÁFICAS}

1. ABE, L.T.; DA MOTA, R.V.; LAJOLO, F.M.; GENOVESE, M.I. Compostos fenólicos e capacidade antioxidante de cultivares de uvas Vitis labrusca L. e Vitis vinifera L. Ciência e Tecnologia de Alimentos, Campinas, v. 27, n. 2, p. 394-400, abr./jun. 2007.

2. ADEGOKE, G.O.; KUMAR, M.V.; GOPALAKRISHNA, A.G.; VARADAJ, M.C.; SAMBAIAH, K.; LOKESH, B.R. Antioxidants and lipids oxidation in foods - A critical appraisal. Journal of Food Science and Technology, Oxford, v.35, n.4, p.283-298, 1998. 
3. AGOSTINI, L.R.; JIMÉNEZ, M.J.M.; RAMÓN, A.N.; GÓMEZ, A.A. Determinación de la capacidad antioxidante de flavonoides en frutas $y$ verduras frescas y tratadas térmicamente. Archivos Latinoamericanos de Nutrición, Caracas, v.54, n.1, 2004.

4. ANDRADE, C.A.; COSTA, C.K.; MIGUEL, M.D.; MIGUEL, O.G.; KERBER, V.A. Determinação do conteúdo fenólico e avaliação da atividade antioxidante de Acacia podalyriifolia. Revista Brasileira de Farmacognosia, Maringá, v.17, p.231-235, abr./jun. 2007.

5. ANDREO, D.; JORGE, N. Antioxidantes naturais: técnicas de extração. Boletim CEPPA, Curitiba v. 24, n. 2, p. 319-336, jul./dez. 2006

6. BAILEY, A.E. Bailey's Industrial Oil and Fat Products, 5.ed. New York: JOHN WILEY, 1996.

7. BALASUNDRAM, N.; SUNDRAM, K.; SAMMAN, S. Phenolic compounds in plants and agroindustrial by-products: antioxidant activity, occurrence, and potential uses. Food Chemistry, London, v.99, n.1, p.191-203, 2006.

8. BARBUT, S.; JOSEPHSON, D.B.; MAURER, A.J. Antioxidant properties of rosemary oleoresin in Turkey sausage. Journal of Food Science, Chicago, v.50, n.5, p.1356-1363, 1985.

9. BATISTA, E,C,S,; COSTA, A.G.V.; PINHEIRO-SANT'ANA, H.M. Adição da vitamina E aos alimentos: implicações para os alimentos e para a saúde humana. Revista de Nutrição, Campinas, v.20, p.525-535, set./out., 2007.

10. BEM-AMOTZ, A.; FISHLER, R. Analysis of carotenoids with emphasis on 9-cis- $\beta$-carotene in vegetables and fruits commonly consumed in Israel. Food Chemistry, London, v.62, n.4, p.515-520, 1998.

11. BIANCHINI, R.; PENTEADO, M.V.C. Vitamina E. In: Vitaminas: aspectos nutricionais, bioquímicos, clínicos e analíticos. Barueri: MANOLE, 2003. 600p.

12. BOBBIO, P.A.; BOBBIO, F.O. Química do Processamento de Alimentos. 3.ed. São Paulo: VARELA, 2001. 143p.

13. BRASIL. Portaria n.1.004, de 11 de dezembro de 1998. Regulamento Técnico: Atribuição de Função de Aditivos, Aditivos e seus Limites Máximos de uso para a Categoria 8 - Carne e Produtos Cárneos. Agencia Nacional de Vigilância Sanitária. Disponível em: http://www.anvisa.gov.br/e-legis/. Acesso em: 8 set. 2008.

14. BROINIZI, P.R.B.; ANDRADE-WARTHA, E.R.S.; SILVA, A.M.O.; NOVOA, A.J.V.; TORRES, R.P.; AZEREDO, H.M.C.; ALVES, R.E.; MANCINI-FILHO, J. Avaliação da atividade antioxidante dos compostos fenólicos naturalmente presentes em subprodutos do pseudofruto de caju (Anacardium occidentale L.). Ciência e Tecnologia de Alimentos, Campinas, v.27, p.902-908, out./dez. 2007.

15. BURTON, G.W.; TRABER, M.G.; ACUFF, R.V.; WALTERS, D.N.; KAYDEN, H.; HUGHES, L.L. Human plasma and tissue a-tocopherol concentrations in response to supplementation with deuterated natural and synthetic vitamin E. American Journal of Clinical Nutrition, Chicago, v.64, p.669-684, 1998.

16. CASTILHO, C.C. Qualidade da carne. São Paulo: Varela, 2006. 240p.

17. COMBS, G.F. The Vitamins Fundamental Aspects in Nutrition and Health. 2.ed. New York: ACADEMIC PRESS, 1998.

18. CRUCES-BLANCO, C.; CARRETERO, A.S.; BOYLE, E.M.; GUTIÉRREZ, A.F. The use of dansyl chloride in the spectrofluorimetric determination of the synthetic antioxidant butylated hydroxyanisole in foodstuffs, Talanta, v.50, p.1099-1108, 1999. 
19. DE WINNE, A.; DIRINCK, P. Studies on vitamin E and meat quality. Effect of feeding high vitamin $E$ levels to pigs on the sensory and keeping quality of cooked ham. Journal of Agricultural and Food Chemistry, v.45, p.4309-4317, 1997.

20. DECKER, E.A.; XU, Z. Minimizing rancidity in muscle foods. Food Tecnology, v.52, n.10, p.54-59, 1999.

21. EL-ALIM, S.S.L.A.; LUGASI, A.; HOVARI, G.; DWORSCHAK, E. Culinary herbs inhibit lipid oxidation in raw and cooked minced meat patties during storage. Journal of the Science of Food and Agriculture, London, v.79, n.2, p.277-285, 1999.

22. EMPSON, K.L., LABUZA, T.P., GRAF, E. Phytic acid as a food antioxidant. Journal of Food Science, Chicago, v.56, n.2, p.560-563, 1991.

23. EXARCHOU, V.; NENADIS N.; TSIMIDOU, M.; GEROTHANASSIS, I.P.; TROGANIS, A.; BOSKOU, D. Antioxidants activities and phenolic composition of extracts from greek oregano, greek sage and summer savory. Journal of Agriculture and Food Chemistry, Washington, v.50, n.19, p.5294-5299, 2002.

24. FERNÁNDEZ-LÓPEZ, J.; ZHI, N.; ALESON-CARBONELL, L.; PEREZ-ALVAREZ, J.A.; KURI, V. Antioxidant and antibacterial activities of natural extracts: application in beef meatballs. Meat Science, Barking, v.69, n.3, p.371-380, 2005.

25. HARBACH, A.P.R.; COSTA, M.C.R.; SOARES, A.L.; BRIDI, A.M.; SHIMOKOMAKI, M.; SILVA, C.A; IDA, E.I. Dietary corn germ containing phytic acid prevents pork meat lipid oxidation while maintaining normal animal growth performance. Food Chemistry, London, v.100, p.163-1633, 2007.

26. HERRERO, M.; CIFUENTES, A.; IBANEZ, E. Sub and supercritical fluid extraction of functional ingredients from different natural sources: plants, food-by-products, algae and microalgae: a review. Food Chemistry, London, v.98, n.1, p.136-148, 2006.

27. ISABEL, B.; LOPEZ-BOTE, C.J.; REY, A.I.; ARIAS, R.S. Influence of dietary a-tocopheryl acetate supplementation of pigs on oxidative deterioration and weight loss in sliced drycured ham. Meat Science, Barking , v.51, p.227-232, 1999.

28. JARDINI, F.A.; FILHO, J.M. Avaliação da atividade antioxidante em diferentes extratos da polpa e sementes da romã (Punica granatum, L.). Revista Brasileira de Ciências Farmacêuticas, São Paulo, v.43, n.1. jan./mar. 2007.

29. KAHKONEN, M.P.; HEINONEN, M. Antioxidant activity of anthocyanins and their aglycons. Journal of Agricultural and Food Chemistry, v.51, n.3, p.628-633, 2003.

30. LAGE, M.E. Suplementação nutricional de novilhos nelore com a-tocoferol (Vitamina E) e seus efeitos na qualidade da carne. 2004. 96 f. Tese (Doutorado em Ciência de Alimentos) - UNICAMP, Campinas, SP.

31. LEAL, P.F.; BRAGA, M.E.; SATO, D.N.; CARVALHO, J.E.; MARQUES, M.O.; MEIRELES, M.A. Functional properties of spices extracts obtained via supercritical fluid extraction. Journal of Agricultural and Food Chemistry, Easton, v.51, n.9, p.2520-2525, 2003.

32. MADHAVI, D.L.; SALUNKHE, D.K. Antioxidants. In: _ Food Antioxidants: Tecnological, Toxicological, and Health Perspectives. New York: MARCEL DEKKER, 1995.

33. MADSEN, H.L., BERTELSEN, G. Spices as antioxidants. Trends in Food Science and Techology, Amsterdan, v.6, n.8, p.271-277, 1995.

34. MARINOVA, E.M.; YANISHLIEVA, N.V. Inhibited oxidation of lipids II: Comparison of the antioxidative properties of some hydroxy derivatives of benzoic and cinnamic acids. FettWissenschaft Technologie, Leinfeldem-Echterdingen, v.94, n.11, p.428-432, 1992. 
35. MARIUTTI, L.R.B.; BRAGAGNOLO, N. Revisão: Antioxidantes Naturais da Família Lamiaceae. Aplicação em Produtos Alimentícios. Brazilian Journal of Food Technology, v. 10, p. 96-103, abr./jun. 2007.

36. MELO, E.A.; GUERRA, N.B. Ação antioxidante de compostos fenólicos naturalmente presentes em alimentos. Boletim SBCTA, Campinas, v.36, p.1-11, jan./jun. 2002.

37. MOURE, A.; CRUZ, J.M.; FRANCO, D.; DOMINGUEZ, J.M.; SINEIRO, J.; DOMINGUEZ, H.; NUÑEZ, J.M.; PARAJÓ, J.C. Natural antioxidants from residual sources- A Rewiew. Food Chemistry, London, v.72, p.145-171, 2001.

38. MUKAI, F.H.; GOLDSTEIN, D.B. Mutagenicity of malonaldehyde, a decomposition product of peroxidized polyunsaturated fatty acids. Science, New York, v.191, 1976.

39. NISSEN, L.R.; BYRNE, D.V.; BERTELSEN, G.; SKIBSTED, L.H. The antioxidative activity of plant extracts in cooked pork patties as evaluated by descriptive sensory profiling and chemical analysis. Meat Science, Barking, v.68, n.3, p.485-495, 2004.

40. O'GRADY, M.N.; MONAHAN, F.J.; BURKE, R.M.; ALLEN, P. The effect of oxygen level and exogenous a-tocopherol on the oxidative stability of minced beef in modified atmosphere packs. Meat Science, Barking, v.55, p.39-45, 2000.

41. ORDÓÑEZ, J.A. Tecnologia de alimentos: componentes dos alimentos e processos. Porto Alegre: ARTMED, 2005.

42. PADILHA, A.D.G. Antioxidante natural de erva mate na conservação da carne de frango in vivo. 2007. 97 f. Dissertação (Mestrado em Ciência e Tecnologia dos Alimentos) - Universidade Federal de Santa Maria, Santa Maria, RS.

43. PIEDADE, K.R. Uso de ervas aromáticas na estabilidade oxidativa de filés de sardinha (Sardinella brasiliensis) processados. 2007. 161 f. Dissertação (Mestrado em Ciências e Tecnologia de Alimentos) - Universidade de São Paulo, Piracicaba, SP.

44. RAMALHO, V.C.; JORGE, N. Antioxidantes utilizados em óleos, gorduras e alimentos gordurosos. Química Nova, São Paulo, v.29, n.4, p.755-760, 2006.

45. RESSURRECCION, A.V.A.; REYNOLDS, A.E. Evaluation of natural antioxidants in frankfurters containing chicken and pork. Journal of Food Science, Chicago, v.55, p.629-654, 1990.

46. SAMEJIMA, K.; KANAZAWA, K.; ASHIDA, H.; DANNO, G.I. Luteolin: a strong antimutagen against dietary carcinogen, Trp-P-2, in peppermint, sage and thyme. Journal of Agricultural and Food Chemistry, Washington, v.43, n.2, p.410-414, 1995.

47. SÁNCHEZ-ESCALANTE, A.; DJENANE, D.; TORRESCANO, G.; BELTRÁN, J.A.; RONCALÉS, P. Antioxidant action of borage, rosemary, oregano and ascorbic acid in beef patties packaged in modified atmosphere. Journal of Food Science, v.68, p.339-344, 2003.

48. SEBRANEK, J.G.; SEWALT, V.J.H.; ROBBINS, K.L.; HOUSER, T.A. Comparison of a natural rosemary extract and $\mathrm{BHA} / \mathrm{BHT}$ for relative antioxidant effectiveness in pork sausage. Meat Science, Barking, v.69, n.2, p.289-296, 2005.

49. SHAMBERGER, R.J.; ANDREONE, T.L.; WILLIS, C.E. Antioxidants and cancer. Malonaldehyde has imitating as a carcinogenic. Journal of the National Cancer Institute, v.53, p.1771-1773, 1974

50. SHERWIN, E.R. Antioxidants. In: Food Antioxidants: Tecnological, Toxicological, and Health Perspectives. New York: MARCEL DEKKER, 1995.

51. SHIMOKOMAKI, M.; OLIVO, R.; TERRA, N.N.; FRANCO, B.D.G.M. Atualidades em ciência e tecnologia de carnes. São Paulo: VARELLA, 2006, 230p. 
52. SILVA, M.R.; SILVA, M.A.A.P. Aspectos nutricionais de fitatos e taninos. Revista de Nutrição, Campinas, v.12, p.5-19. jan./abr. 1999.

53. SIVAM, G. Analysis of Flavonoids. In: Methods of Analysis for Functional Foods and Nutraceuticals. 2.ed. New York: CRC PRESS, 2002. 416p.

54. SKERGET, M.; KOTNIK, P.; HADOLIN, M.; RIZNER-HRAS, A.; SIMONIC, M.; KNEZ, Z. Phenols, proanthocyanidins, flavones and flavonols in some plant materials and their antioxidant activities. Food Chemistry, Longon, v.89, n.2, p.191-198, 2005.

55. SOARES, S.E. Ácidos fenólicos como antioxidantes. Revista de Nutrição, Campinas, v.15, n.1, p.3-16, 2002.

56. SOUZA, M.A.A. Casca da batata inglesa (solanum tuberosum) na proteção antioxidante da carne de frango. 2006. 73 f. Dissertação (Mestrado em Ciência e Tecnologia dos Alimentos) - Universidade Federal de Santa Maria, Santa Maria, RS.

57. SOUZA, V.L.F.; SILVA, R.S.S.F. Dietary vitamin E supplementation on cholesterol and cholesterol oxides of pig meat and cooked ham. Brazilian Archives of Biology and Technology, Curitiba, v.49, p.197-205, 2006.

58. TOZER, K.N. Qualin improvement and shelf-life extension of fish filets from three aquaculture species. 2001. Dissertação (Mestrado) - University of Guelph. Ontário, Canadá.

59. TRINDADE, R.A. Influência de antioxidantes naturais sobre o perfil lipídico de hambúrgueres bovinos submetidos à irradiação por ${ }^{60} \mathrm{CO}$ e aceleradores de elétrons. 2007. 112 f. Dissertação (Mestrado em Ciências em Tecnologia Nuclear) Instituto de Pesquisas Energéticas e Nucleares. São Paulo, SP.

60. VENDRAMINI, A.L.A.; TRUGO, L.C. Phenolic Compounds in Acerola Fruit (Malpighia punicifolia, L.). Journal of the Brazilian Chemical Society, São Paulo, v.15, n.5, p.664668, 2004.

61. VON GADOW, A.; JOUBERT, E.; HANSMANN, C.F. Comparison of the antioxidant activity of aspalathin with that of other plant phenols of rooibos tea (Aspalathus linearis), atocopherol, BHT and BHA. Journal Agriculture and Food Chemistry, Washington DC, v.45, p.632-638, 1997.

62. WITSCHI, H.P. Enhanced tumour development by butylated hidroxytoluene (BHT) in the liver, lung and gastro-intestinal tract. Food Chemical and Toxicology, Oxford, v.24, n.10/11, p.1127-1130, 1986.

63. WONG, J.W.; HASHIMOTO, K.; SHIBAMOTO, T. Antioxidant activities of rosemary and sage extracts and vitamin $E$ in a model meat system. Journal of Agricultural and Food Chemistry, Washington, v.43, n.10, p.2707-2712, 1995.

64. WURTZEN, G. Scientific evaluation of the safety factor for the acceptable daily intake. Case study: butylated hydroxyanisole (BHA). Food Additives and Contaminants, v.10, n.3, p.307-314, 1993. 